NASA Technical Memorandum 4596

\title{
Development of a Low-Aspect Ratio Fin for Flight Research Experiments
}

David M. Richwine

PRC Inc.

Edwards, California

John H. Del Frate

Dryden Flight Research Center

Edwards, California

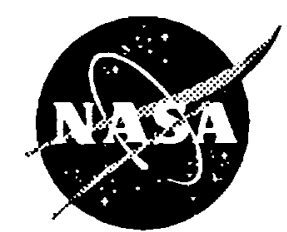

National Aeronautics and Space Administration

Office of Management

Scientific and Technical Information Program 1994 


\title{
DEVELOPMENT OF A LOW-ASPECT RATIO FIN FOR FLIGHT RESEARCH EXPERIMENTS
}

\author{
David M. Richwine* \\ PRC Inc. \\ Edwards, CA 93523-0273 \\ John H. Del Frate* \\ NASA Dryden Flight Research Center \\ Edwards, CA 93523-0273
}

\section{Abstract}

A second-generation flight test fixture, developed at NASA Dryden Flight Research Center, offers a generic testbed for aerodynamic and fluid mechanics research. The new fixture, a low-aspect ratio vertical fin shape mounted on the centerline of an F-15B aircraft lower fuselage, is designed for flight research at Mach numbers up to 2.0. The new fixture is a composite structure with a modular configuration and removable components for functional flexibility. This report describes the multidisciplinary design and analysis approach used to develop the fixture. The approach integrates conservative assumptions with simple analysis techniques to minimize the time and cost associated with its development. Presented are the principal disciplines required for this effort, which include aerodynamics, structures, stability, and operational considerations. In addition, preliminary results from the first phase of flight testing are presented. Acceptable directional stability and flow quality are documented and show agreement with predictions. Future envelope expansion activities will minimize current limitations so that the fixture can be used for a wide variety of high-speed aerodynamic and fluid mechanics research experiments.

\section{Nomenclature}

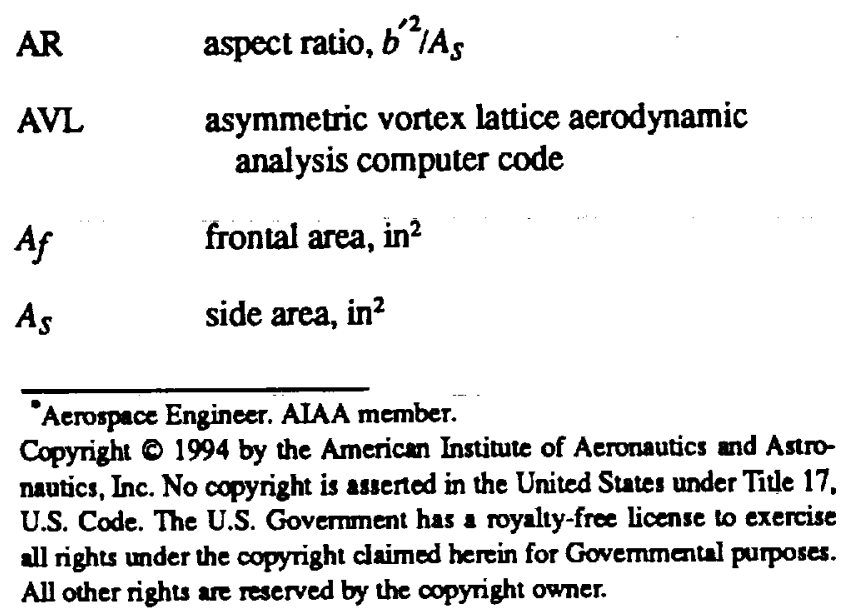

\begin{tabular}{ll}
$b^{\prime}$ & vertical span (on fixture), in. \\
$C_{D}$ & drag coefficient at $\beta=0^{\circ}$ \\
$C_{r}$ & side force coefficient (on fixture) \\
$C_{n \beta}$ & static directional stability, deg \\
$c$ & chord (on fixture), in. \\
F.S. & fuselage station, in. \\
FTF & (original) flight test fixture \\
FTF-II & new flight test fixture \\
$F_{x}$ & frontal force (positive aft), lb \\
$F_{y}$ & side force (positive left), lb \\
$F_{z}$ & normal force (positive down), lb \\
$M$ & Mach number \\
\hline MAC & mean aerodynamic chord (on aircraft) \\
KCAS & calibrated airspeed, knots \\
$q$ & dynamic pressure, lb/ft \\
$\boldsymbol{q}$ & width (on fixture), in. \\
$x / b^{\prime}$ & percent chord (on fixture) \\
$\beta$ & angle of attack, deg \\
\hline & angle of sideslip, deg \\
\hline &
\end{tabular}

\section{Introduction}

In 1963, NASA Dryden Flight Research Center constructed a low-aspect ratio fin-like shape called the flight 
test fixture (FTF) for installation on the lower fuselage of an F-104 aircraft (fig. 1). Since that time, the original FTF has served as a generic testbed for more than 20 aerodynamic and fluid mechanics research experiments. The capabilities and utility of the FTF have been documented frequently, and some of those documents are included as references. ${ }^{1-8}$ In the past few years, NASA Dryden has begun phasing out the aging F-104 aircraft resulting in an effort to identify a new testbed aircraft and to develop a larger and more versatile fixture with similar capabilities. An F-15B was chosen as the primary testbed aircraft for the new flight test fixture (FTF-II) mainly because of its availability and high potential for acceptable flow quality combined with a large airspeed envelope.

This report describes the multidisciplinary design and analysis approach used to develop the new fixture. This approach integrated conservative assumptions with simple analysis techniques to minimize the time and cost associated with developing the FTF-II. A simple, multiphased fight test approach was also used to validate assumptions and analysis.

\section{FTF-II Description}

The FTF-II was installed on the lower fuselage centerline pylon location of an F-15B aircraft (fig. 2) using hardware similar to that used by operational centerline tanks. The FTF-II has self-contained research capabilities so that

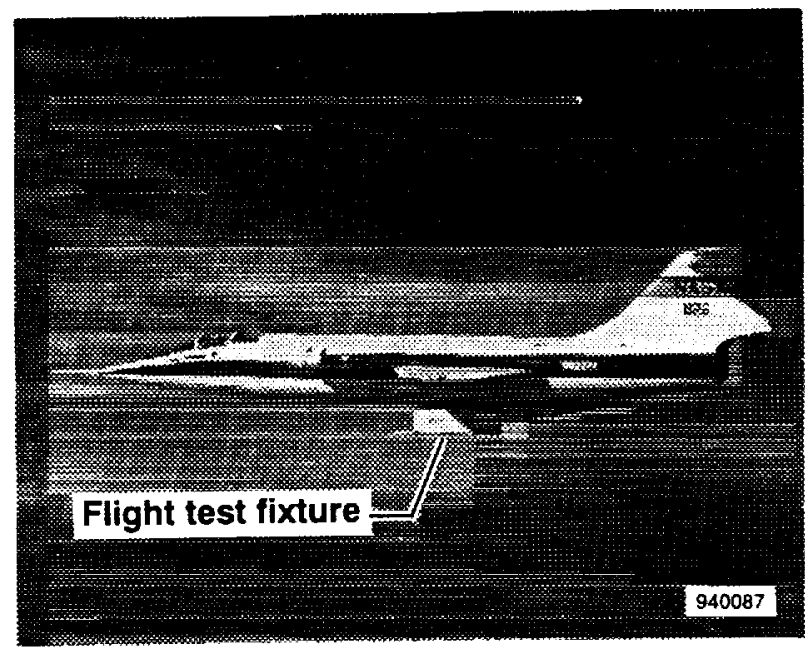

Figure 1. Original FTF installed on lower fuselage of F-104 aircraft.

only aircraft power to the fixture is required. The fixture's maximum estimated weight is $500 \mathrm{lb}$ including all research systems, but it is smaller, lighter, and has less aerodynamic frontal drag than an empty 660-gal centerline tank that is routinely carried by an F-15 aircraft. The FTFII is a low-aspect ratio fin-like shape similar to the original FTF, but is larger to allow more volume and surface area for aerodynamic experiments. As shown in figures 3 and 4 , the new fixture is 107 in. long $(c), 32$ in. high $(b)$, and 8 in.

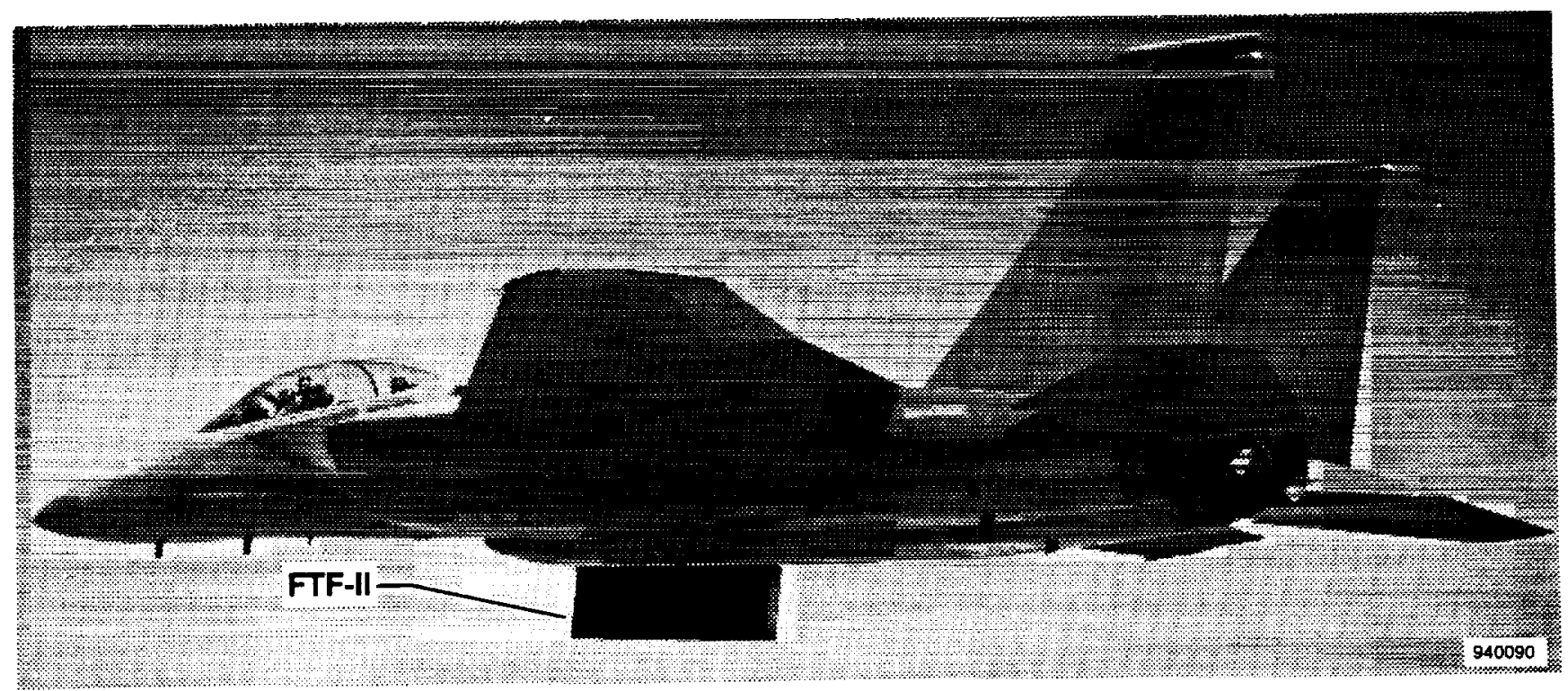

Figure 2. FTF-II installed on lower fuselage centerline pylon location of F-15B aircraft. 
wide (w) with a $12^{\circ}$ elliptical nose section and blunt trailing edge. The all-composite structure is capable of Mach $(M) 2.0$ and dynamic pressure $(q)$ of $2176 \mathrm{lb} / \mathrm{ft}^{2}$.

As shown in figures 4(a) and 4(b), the FTF-II is modular and consists of a basic pylon structure with a replaceable nose section, side panels, and vertical test article so that the configuration can be modified to satisfy a variety of flight test requirements. The upper 19 in. of the fixture, the avionics pylon, is a permanent structure that houses avionics, permanent research instrumentation systems, and other support equipment common to most fight experiments. The lower 13 in. is the vertical test article that, in the current configuration, matches the contour of the upper avionics pylon. The vertical test article is removable and may be replaced by other aerodynamic shapes. Only instrumentation specific to individual research experiments is installed in the vertical test article.

All side panels on the FTF-II are removable with quick internal access through the four left-side panels using external fasteners flush with the surface. The two

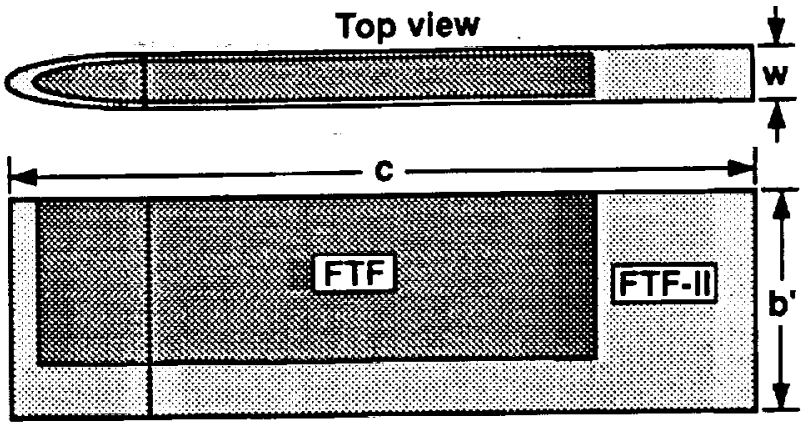

Left side view

\begin{tabular}{c|c|c} 
& FTF & FTF-II \\
\hline c (in.) & 80.0 & 107.0 \\
$b^{\prime}$ (in.) & 24.0 & 32.0 \\
w (in.) & 6.0 & 8.0 \\
$A_{\text {f }}$ (in 2$)$ & 144 & 256 \\
$\left.A_{\text {(in }}{ }^{2}\right)$ & 1920 & 3424 \\
AR & 0.60 & 0.60
\end{tabular}

940047

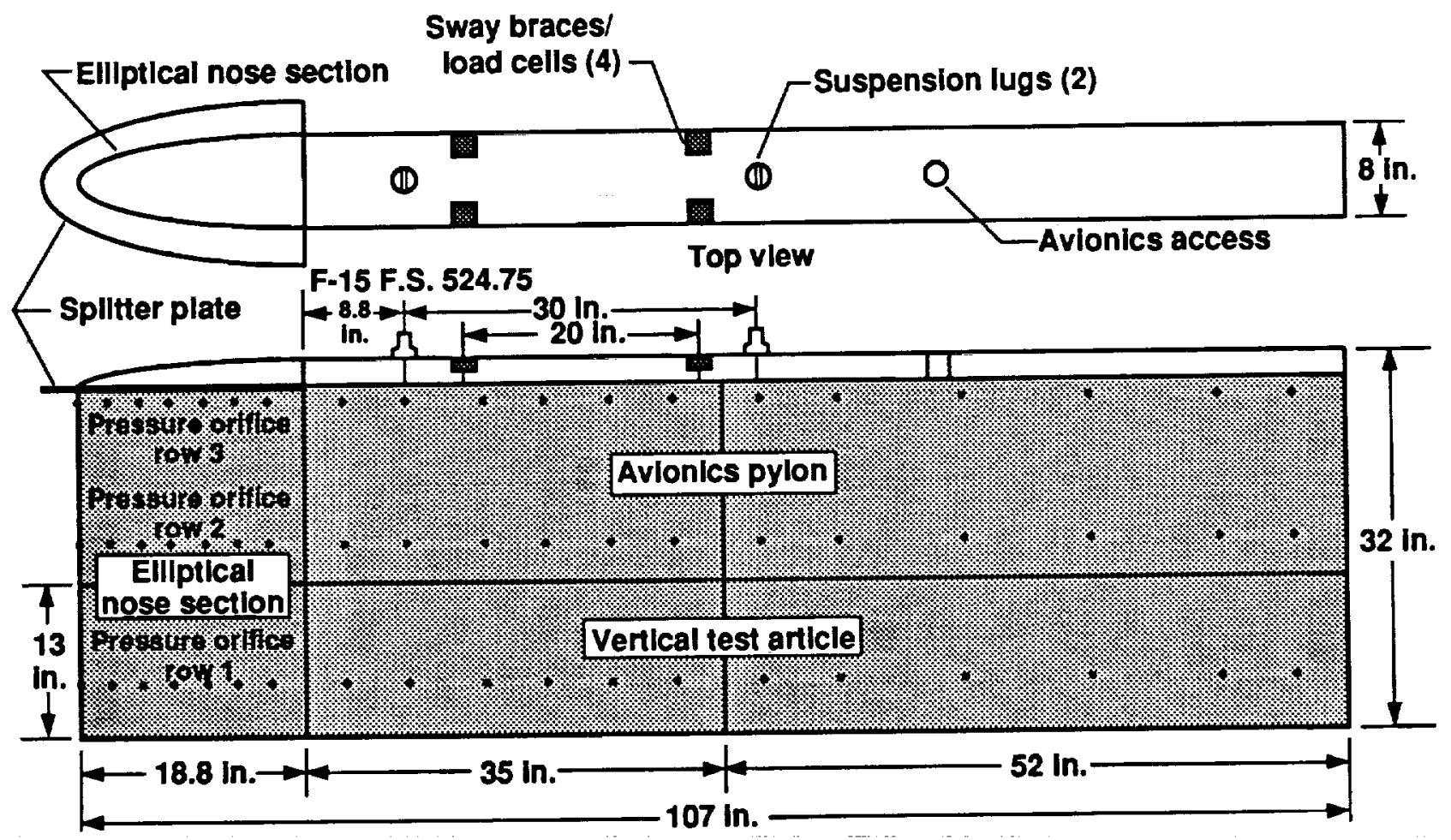

Left side view

90048

(a) Top and left side views.

Figure 4. FIF-II schematic diagrams. 


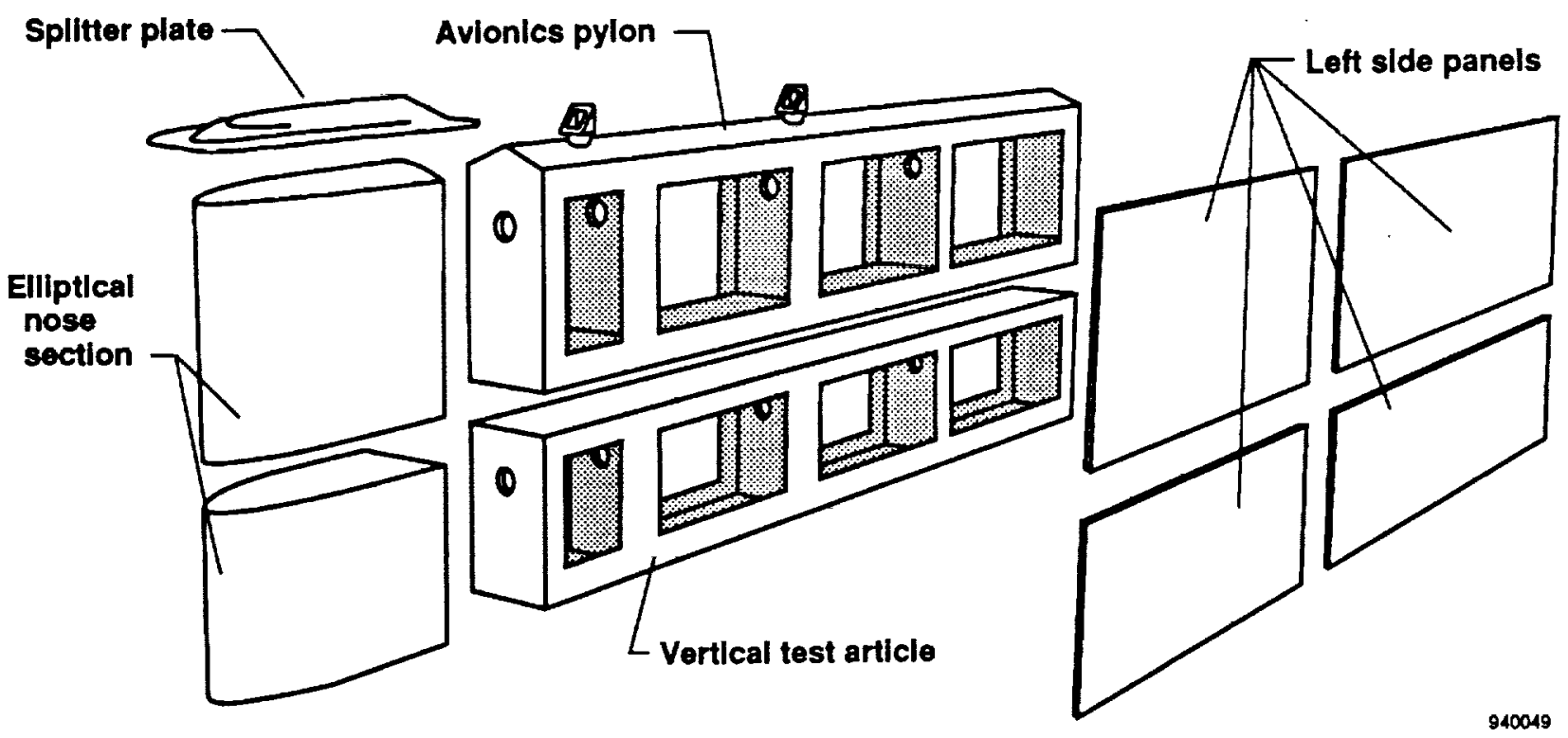

(b) Exploded isometric view.

Figure 4. Concluded.

right side panels (not shown in fig. 4) extend the length of the fixture and are attached using internal fasteners to minimize discontinuities for aerodynamic experiments such as surface flow-visualization studies. The $12^{\circ}$ elliptical nose section is positioned in the forward 18.8 in. and either of its two sections can be removed from the avionics pylon or the vertical test article independently. A removable splitter plate was installed onto the upper portion of the nose section for improved flow quality. Provisions were also made for a removable airdata probe near the bottom of the vertical test article nose section. The airdata probe, when installed, provides static and total pressure, angle of attack, and angle of sideslip to measure local free-stream conditions just forward of the fixture.

\section{Design Philosophy and Approach}

The conceptual phase in the design of the fixture considered a wide variety of design constraints and lessons leamed from 30 years of flight testing with the original FTF at NASA Dryden. Obtaining acceptable flow quality for aerodynamics and fluid mechanics research experiments while maintaining a functionally flexible configuration similar in shape to the FTF was the primary design objective. The design goals also included providing a simple and low-risk structure that could be flown at maximum airspeed with minimal operational limitations on the carrier aircraft. Gaining practical experience with composites was a secondary goal since smooth aerodynamic surfaces can be easily fabricated and modified using these materials.
These design goals affected a variety of disciplines such as aerodynamics, structures, aircraft stability, and flight operations. These constraints reinforced the need for an integrated approach with simple design and analysis techniques. The following sections present an overview of the four primary discipline areas exercised in developing the FTF-II.

\section{Aerodynamics}

Aerodynamic considerations of the FTF-II configuration were key during the design phase of the fixture to determine a desirable aerodynamic shape with a long chord for higher Reynolds number experiments. Because obtaining acceptable flow quality was a key design objective, flowvisualization studies were performed to optimize fixture shape and resulting flow quality. The other aspect of the aerodynamic analysis was estimating the aerodynamic loads on the structure. These efforts were performed concurrently so that both of these considerations were addressed using a simple, yet balanced, technique.

\section{Water-Tunnel Visualization Studies}

Predicting flow quality can be made into a very simple or complex procedure, depending on the required accuracy of the effort. One of the more simple approaches is to conduct water-tunnel studies to obtain a useful macroscopic view of the flow streamlines over the configuration of interest at subsonic speeds. These studies also allow researchers to look at a variety of configurations with 
minimal cost or schedule impact to the project. For this effort, a $1 / 48$-scale plastic model of the aircraft was purchased, and several fixture shapes at various locations were installed and tested in the water tunnel at NASA Dryden's Flow Visualization Facility. Initial studies of the F-15 and original FTF, with simulated inlet flow, generated baseline results that could be compared with past flow-visualization studies of the original FTF flown on the F-104. In general, results showed favorable comparisons in the flow streamlines, with slightly more downwash effects on the upper portion of the original FTF on the F-104.

The F-15/FTF-II configuration was tested at multiple forward and aft locations along the centerline pylon. The investigation at each location focused on several minor configuration changes at angle of attack $(\alpha)$ and sideslip $(\beta)$ of $0^{\circ}$. Angles of atlack up to $25^{\circ}$ and sideslips of $\pm 15^{\circ}$ were also studied to verify that the generation of vortices or other effects did not create undesirable flow over the aircraft or fixture. No undesirable flow effects within the anticipated $\alpha$ and $\beta$ limits of the F-15 were identified. Forward and aft translation of the fixture along the centerline pylon had minimal impact on overall flow quality. Farther aft locations appeared to have slightly less downwash effects from the aircraft and centerline pylon than more forward locations. Combinations of potential fairings and splitter plates were also tested (fig. 5). As shown in figure 5(a), fairings between FTF-II and the aircraft centerline pylon, regardless of their size, had little positive effect on the flow streamlines on the fixture.

A full-chord splitter plate on the top of the fixture was tested (fig. 5(b)) but appeared to reduce only slightly the downwash effects from the aircraft and centerline pylon while $\alpha=0^{\circ}$ and $\beta=0^{\circ}$. When $\alpha \neq 0^{\circ}$ or $\beta \neq 0^{\circ}$, the full-chord splitter plate tended to degrade the flow quality and to generate a vortex. A smaller splitter plate along the length of the nose section that extended $3.0 \mathrm{in}$. (full scale) beyond the surface contour of the $12^{\circ}$ elliptical nose section was found to be the most effective at reducing local downwash effects from the leading edge of the aircraft pylon without creating other undesirable aerodynamic effects. Figure 6 shows the flow streamlines and resulting expected subsonic flow quality of the final F-15/FTF-II configuration without and with the nose section splitter plate. Because downwash effects were limited to the upper portion of the fixture, the splitter plate was made removable to allow for future flight test evaluation and consideration.

\section{Aerodynamic Loads}

Airspeed and other operational limitations of the F-15 played an important role in determining maximum aerodynamic loads.9 To utilize the maximum operational

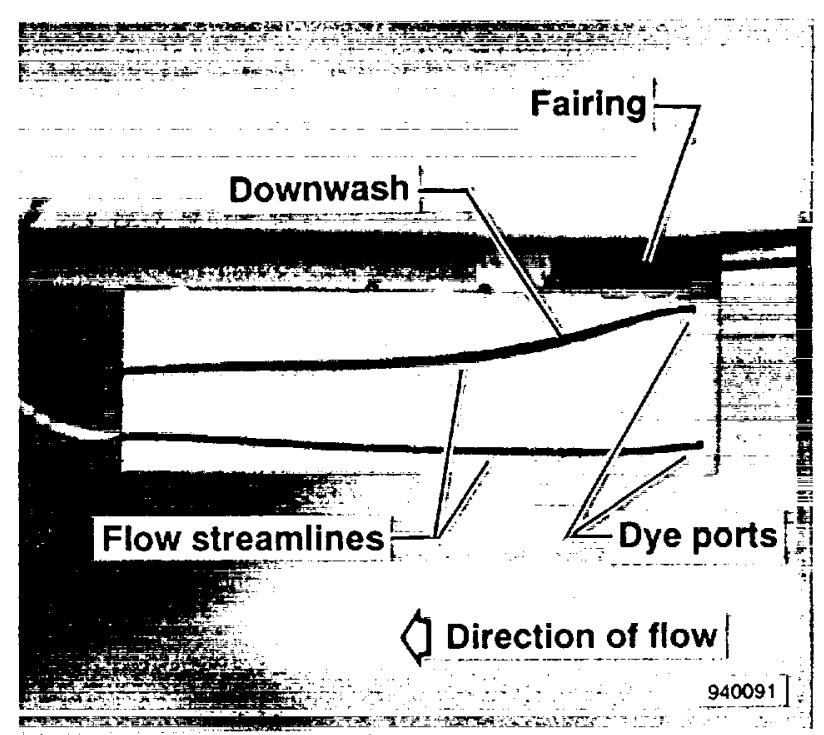

(a) Nose section fairing to fuselage.

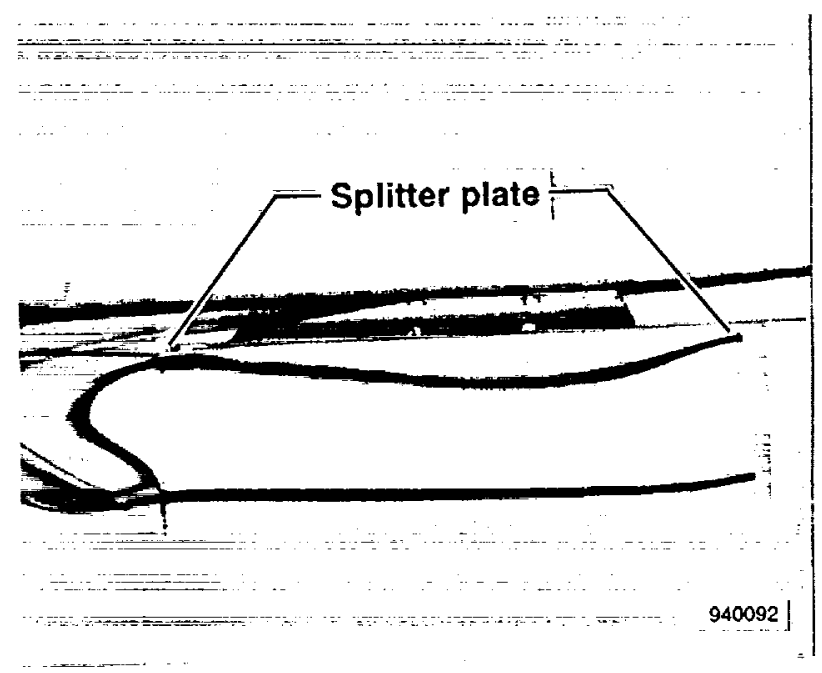

(b) Full-chord splitter plate.

Figure 5. F-15/FTF-II water-tunnel model, forward location, with various proposed configurations, right side view, $\alpha=0^{\circ}, \beta=0^{\circ}$.

capabilities of the F-15, the airspeed envelope shown in figure 7 was used to determine the potential aerodynamic loads on the fixture. Although the F-15 airspeed envelope with an empty centerline tank is limited to 660 knots calibrated airspeed (KCAS) up to altitudes of $20,000 \mathrm{ft}$, the airspeed envelope without external stores is 800 KCAS. As a conservative measure, the $800 \mathrm{KCAS}$ limit at sea level was selected for the worst-case loading conditions where $q=2176 \mathrm{lb} / \mathrm{ft}^{2}$. Although the F-15 can exceed $M=2.0$, predicted aerothermal effects were used to restrict the fixture to $M=2.0$. 
Since the external geometry of the fixture was expected to vary depending on the research requirement, worst-case drag coefficients were determined and used to calculate design loads. To determine the axial drag, approximations of a worst-case physical shape of the fixture included a nose section with a $30^{\circ}$ total wedge angle and a blunt trailing edge. As shown in figure 8(a), drag coefficients $\left(C_{D}\right)$ for an external centerline tank shape ${ }^{10}$ and several

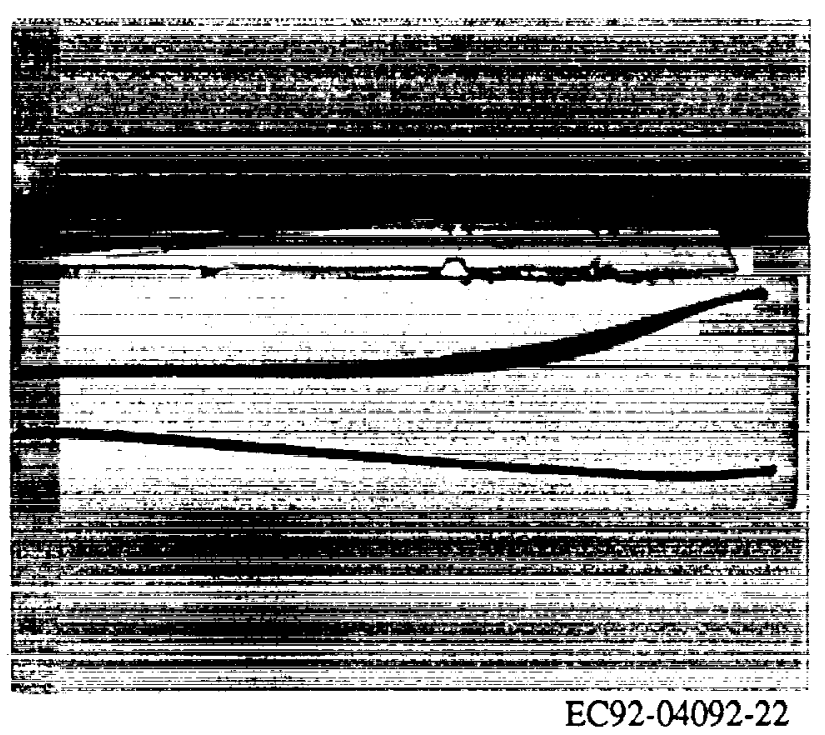

(a) Without nose section splitter plate.

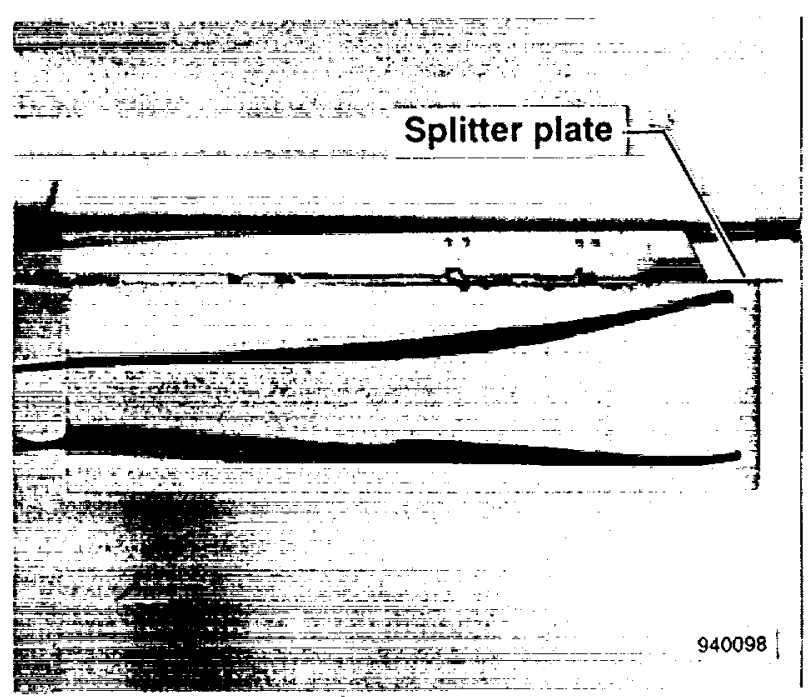

(b) With nose section splitter plate.

Figure 6. F-15/FTF-II water-tunnel model, aft location, right side view, $\alpha=0^{\circ}, \beta=0^{\circ}$.

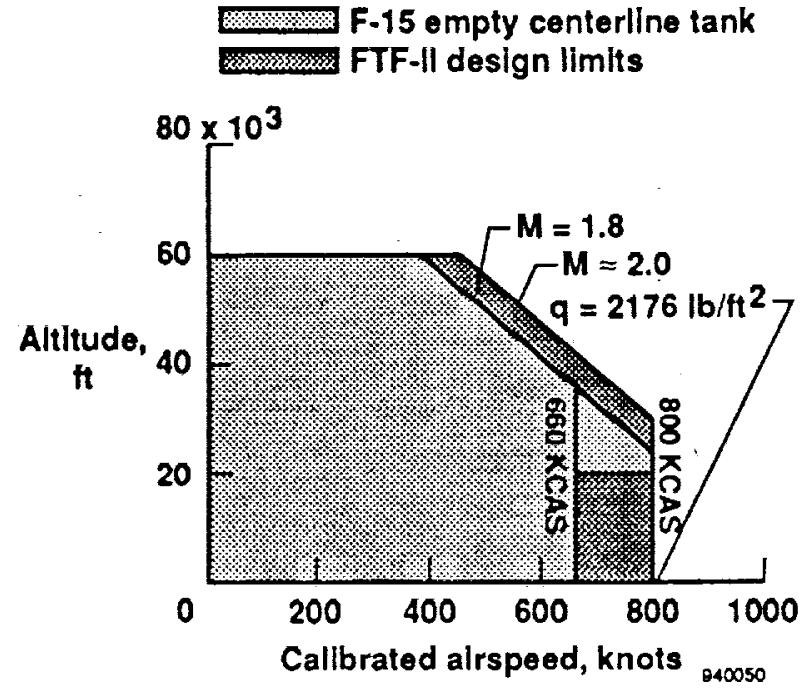

Figure 7. F-15/FTF-II airspeed limitations.

nose section wedge angles were calculated with respect to Mach number for comparison. A combination of friction, ${ }^{11}$ wave, ${ }^{12}$ and base ${ }^{5}$ drag using the reference area of the fixture or tank as appropriate was used to determine $C_{D}$ for each configuration. As a conservative measure, the worst-case $C_{D}=1.07$ in the transonic region with a $30^{\circ}$ total wedge angle was selected to determine maximum axial drag forces of $F_{x}=\left(C_{D}\right)\left(A_{f}\right)(q)=(1.07)\left(256 \mathrm{in}^{2}\right)\left(1 \mathrm{ft}^{2} /\right.$ $\left.144 \mathrm{in}^{2}\right)\left(2176 \mathrm{lb} / \mathrm{ft}^{2}\right)=4139 \mathrm{lb}$.

Worst-case side loads resulting from aerodynamic forces were also evaluated. Data from McDonnell Douglas

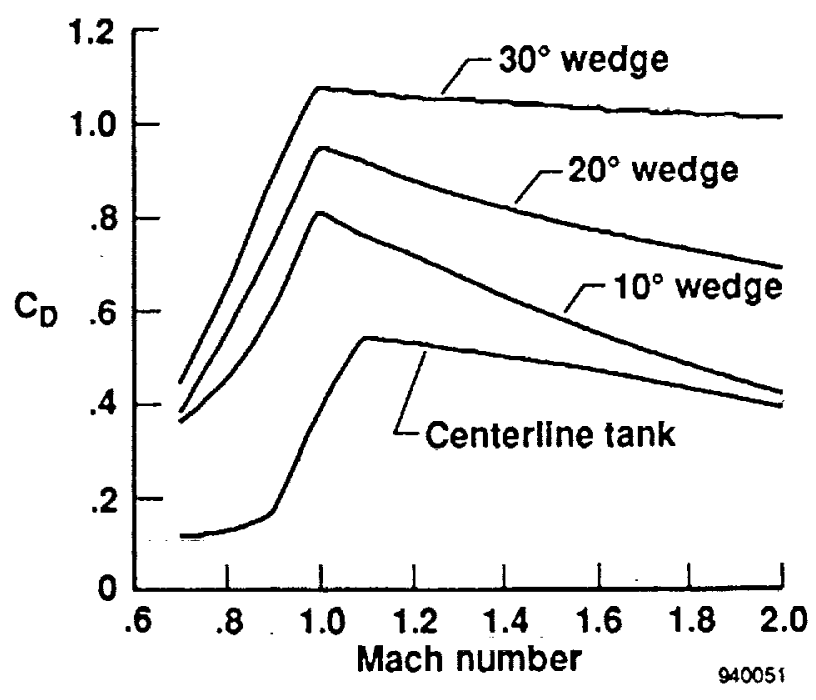

(a) Drag coefficient as a function of Mach number.

Figure 8. Estimation of aerodynamic loads. 


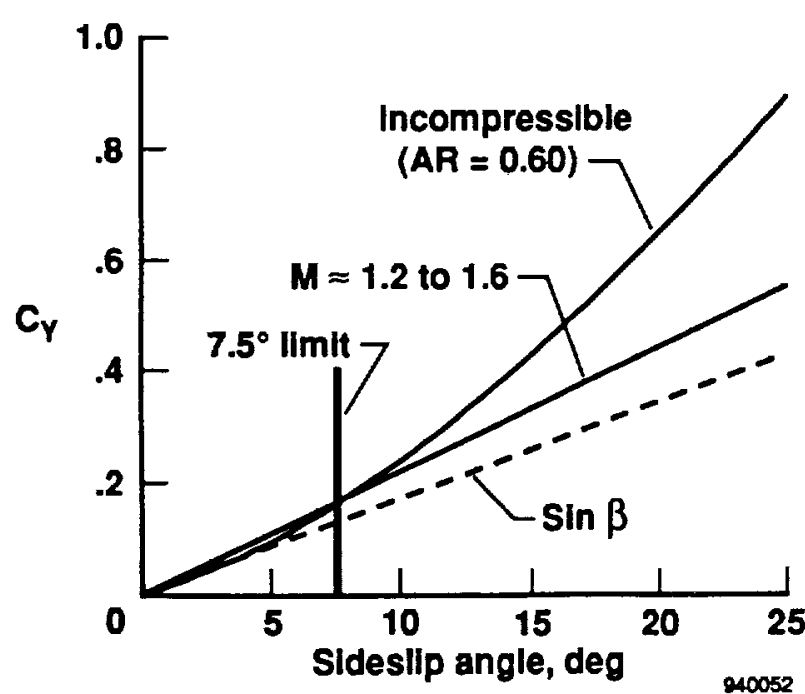

(b) Sideforce coefficient as a function of sideslip angle.

Figure 8. Concluded.

Aircraft Company (St. Louis, Missouri) indicated that a worst-case side load of $\beta q=7500 \mathrm{deg} \cdot \mathrm{lb} / \mathrm{ft}^{2}$ could be achieved if the aircraft were in full afterbumer and a full engine seizure occurred causing asymmetric thrust-drag and higher than normal sideslip conditions. Since this condition has never occurred during the life of the F-15 program, a more realistic design limit of $\beta q=5500 \mathrm{deg} \cdot \mathrm{lb} /$ $\mathrm{ft}^{2}$ was selected based on simulation results and F-15 flight test data. ${ }^{13}$

Side force coefficients $\left(C_{Y}\right)$ as a function of sideslip angle were estimated to reflect worst-case aerodynamic side loads (fig. 8(b)). To reduce $\beta q$ limits into an estimated side load, $\sin \beta$ was used to approximate the projected drag area. Using a flat-plate approximation of the fixture, $C_{Y}$ in relation to $\beta$ was calculated using the approximation of $\sin \beta$ and other data ${ }^{14,15}$ for comparison and validation. As shown, the approximation using $\sin \beta$ shows fair agreement with the incompressible and supersonic data only at low angles of sideslip. As a result, a conservative $\beta$ limit of $\pm 7.5^{\circ}$ was initially imposed on the FTF-II. The approximation using $\sin \beta$ was used to estimate fixture side loads with the $\beta= \pm 7.5^{\circ}$ limit and $\beta q=5500$ $\mathrm{deg} \cdot \mathrm{lb} / \mathrm{ft}^{2}$. The resulting estimation of maximum side drag forces of $F_{y}=(\sin \beta)(q)\left(A_{s}\right)=\left(\sin 7.5^{\circ}\right)\left(733 \mathrm{lb} / \mathrm{ft}^{2}\right)(3424$ $\left.\mathrm{in}^{2}\right)\left(1 \mathrm{ft}^{2} / 144 \mathrm{in}^{2}\right)=2275 \mathrm{lb}$.

The distribution of axial and side aerodynamic forces were assumed to be distributed uniformly along the fixture vertical span $\left(b^{\prime}\right)$. The distribution of side loads along the fixture chord $(c)$ is a function of aspect ratio $(A R=0.60)$ and Mach number and requires more careful consideration. Typically, the center of pressure for lifting surfaces such as wings is $x / c=0.25$ subsonic and $x / c=$
0.50 during supersonic conditions. Both theory and experimental data also show that very low aspect ratio panels. may have center of pressure locations that are farther forward than on conventional aircraft wings. ${ }^{14-16}$ These data also indicate that a center of pressure as far forward as $x / c$ $=0.10$ could exist at transonic conditions, but that the center of pressure moves aft with increasing sideslip. As a result, a range of center of pressures from $x / c$ of 0.15 to 0.66 were used in the loads analysis.

\section{Structural Design}

The structural design philosophy for the FTF-II was to provide an all-composite structure that was a relatively simple and low risk design that addressed the requirements of the other related disciplines. For example, since the weight of the fixture was not a critical design criteria, a safety factor of 2.25 was used to ensure a conservative structural design. In addition, the structure was designed to be relatively stiff to minimize structural dynamic concerns. Maximum aerodynamic and inertial loads shown in table 1 were used as load conditions that were combined into conservative design limit loads for all flight conditions.

Table 1. Summary of FTF-II applied loads.

\begin{tabular}{rcccc}
\hline \hline No. & Load conditions & $F_{x}$ & $F_{y}$ & $F_{z}$ \\
\hline & Aerodynamic loads & & & \\
1 & $q=2176 \mathrm{bb} / \mathrm{ft}^{2}$ at forward lug & 4139 & 0 & 0 \\
2 & $q=2176 \mathrm{lb} / \mathrm{ft}^{2}$ at aft lug & 4139 & 0 & 0 \\
3 & $\beta q=5500$ at $x / c=0.15$ & 0 & 2275 & 0 \\
4 & $\beta q=5500$ at $x / c=0.50$ & 0 & 2275 & 0 \\
5 & $\beta q=5500$ at $x / c=0.66$ & 0 & 2275 & 0 \\
& Inertial loads $(500 \mathrm{lb})$ & & & \\
6 & $7.5 \mathrm{~g}$ normal at $x / c=0.33$ & 0 & 0 & 3750 \\
7 & $7.5 g$ normal at $x / c=0.66$ & 0 & 0 & 3750 \\
8 & $1.5 g$ lateral at $x / c=0.33$ & 0 & 750 & 0 \\
9 & $1.5 g$ lateral at $x / c=0.66$ & 0 & 750 & 0 \\
10 & Sway brace-lug preloads & 0 & 0 & 3024 \\
\hline \hline
\end{tabular}

\section{Loads and Stress Analysis}

As shown in table 1, the FTF-II inertial loads were calculated using the estimated fixture weight of $500 \mathrm{lb}$ and applying standard F-15 g-limitations. ${ }^{9}$ Inertial loads were assumed to be uniform with respect to the fixture vertical span with the center of gravity located at $z / b^{\circ}=0.50$. To maintain configuration flexibility, centers of gravity of $x / c$ of 0.33 to 0.66 were used in the loads analysis. Other applied loads shown in table 1 include vertical preloads to the suspension lug-sway brace pairs where the fixture attached to the centerline pylon. Aerodynamic drag loads, where $q=2176 \mathrm{lb} / \mathrm{ft}^{2}$, and side loads, where $\beta q=5500$ 
$\mathrm{deg} \cdot \mathrm{lb} / \mathrm{ft}^{2}$ with centers of pressure at $x / c=0.15,0.50$, and Q.66, are also shown.

As in many design problems, additional assumptions were made because of the statically indeterminate attachment points at the suspension lugs and sway braces. To simplify the analysis, all shear loads were supported at the suspension lugs, and side moment loads were distributed to the leeward forward and aft sway pads. Axial shear loads were distributed so that all of the load applied was at each suspension lug at $z / b^{\prime}=0.50$. Vertical preloads to the suspension lug-sway brace pairs were distributed equally. At load cases where $x / c<0.50,60$ percent of the side moments react at the forward sway brace. Similarly, at load cases where $x / c>0.50,60$ percent of the side moments react at the aft sway brace. By making these simple assumptions, load conditions were combined and the resulting shear and moment free-body diagrams were developed for the most severe loading conditions identified at specific locations within the structure.

A comprehensive stress analysis of each fixture structural component was performed using worst-case design limit shear and/or moment loads, as appropriate. The analysis included the major components of the fixture avionics pylon, test article, nose section, and attachment hardware. Shear and bending stresses were evaluated including bond lines, and panel buckling and bearing. The minimum acceptable number of functional fasteners in each area was determined for future reference. As expected with composites, the regions of most concern were composite bearing and pullout loads at the suspension lugs and other attachment hardware. All margins of safety were positive (where margin of safety was defined as [(ultimate load or stress) $/(2.25$ )(design limit load or stress)] -1 ), with the lowest margin of 0.42 due to bearing loads at the suspension lugs.

\section{Structural Ground Testing}

Structural ground tests are a common way to validate the integrity of structures and are often required for complex structures or when a lower design factor of safety $\leq 1.50$ is used in the design and analysis. Although a design factor of safety of 2.25 was used for the FTF-II, an instrumented test article representative of critical stress areas was fabricated and ground tests were performed to validate the design and fabrication techniques of the composite structure. As shown in figure 9, the test article was representative of the avionics pylon portion of the FTF-II with structure limited to the region around the suspension lugs and sway braces that experience high structural loading. The test article was mounted to a pylon with similar suspension lug and sway brace hardware used on the fixture. Load cells rated at $10,000 \mathrm{lb}$ were installed in between the fixture and four sway brace pads to monitor reaction loads at these locations. Side panels were also installed to best represent the final configuration of the fixture structure. A point load of $4,600 \mathrm{lb}$ was applied near the lower edge of the test article at a range of $x / c=0.15$ to 0.39 to simulate predicted side moment loadings to over 1.50 times the design limit load. Twelve strain gages were installed at various critical locations on the test fixture. All instrumentation was monitored in real time and analyzed in more detail after the ground test.

Seven load tests were completed on the test article with a conservative matrix focused on looking at structure strains and stiffness, and the resulting loads at the sway pad locations. Table 2 shows a summary of these tests. Figure 10 shows typical data from the load tests. The first plot (fig. 10(a)) compares values for a strain gage as a function of the applied load. The strain gage was located in one of the more critical areas around the forward suspension lug, but was well within the acceptable strain levels for carbon-epoxy material. Linear and repeatable strain slopes throughout the structure at all loading conditions indicated that the structure is quite stiff and insensitive to the chord distribution of loads. In addition, the structure was insensitive to configuration changes, such as a loose panel (table 2). Figure 10(b) compares a forward sway pad load cell as a function of applied load. Linear and repeatable reaction loads at the forward sway pad were observed and provided useful information in the design and analysis of the fixture. Results showed that aft sway brace loads were consistently 80 percent of the forward sway brace loads. In addition, about 30 percent of the side moment loads reacted through the suspension lugs instead of entirely through the sway braces. These results indicate that the fixture is quite stiff and insensitive to the chord distribution of loads, but that reaction loads at the

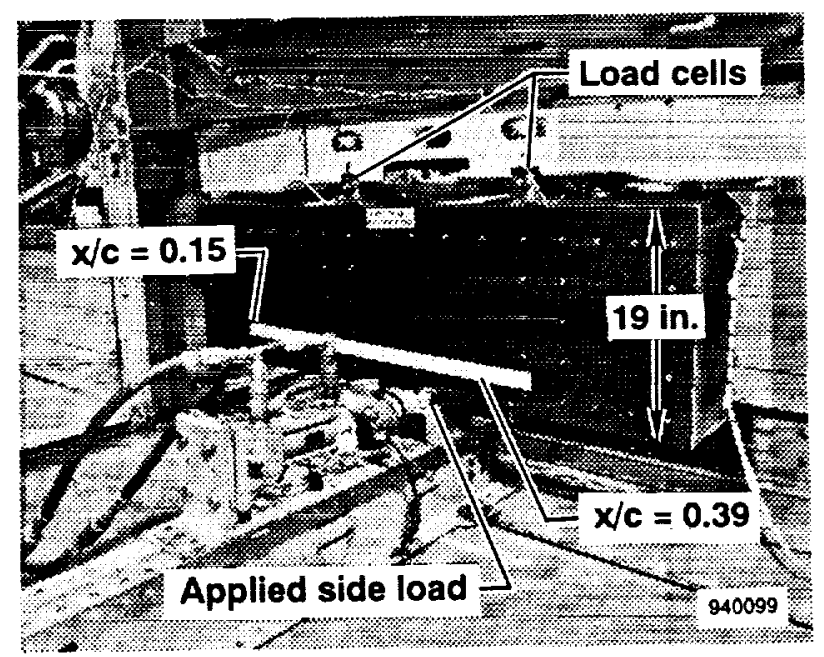

Figure 9. Ground test setup of the instrumented test article. 
Table 2. Structural ground test matrix.

\begin{tabular}{lcccl}
\hline \hline Test & $x / c$ & $\begin{array}{c}\text { Applied } \\
\text { load (lb) }\end{array}$ & $\begin{array}{c}\text { Load } \\
\text { cells }\end{array}$ & \multicolumn{1}{c}{ Comments and load condition } \\
\hline l & 0.39 & 3000 & Yes & Even lug-sway brace load distribution \\
2A & 0.33 & 3000 & Yes & Nominal lug-sway brace load distribution \\
2B & 0.33 & 4600 & No & Same as 2A, 1.5 times design limit load \\
3 & 0.15 & 3000 & Yes & Forward lug-sway brace load distribution \\
4 & 0.15 & 3000 & Yes & Same as 3, loose left side panel \\
5A & 0.33 & 3000 & Yes & Same as 2A, loose left side panel \\
5B & 0.33 & 4600 & No & Same as 5A, 1.5 times design limit load \\
\hline \hline
\end{tabular}

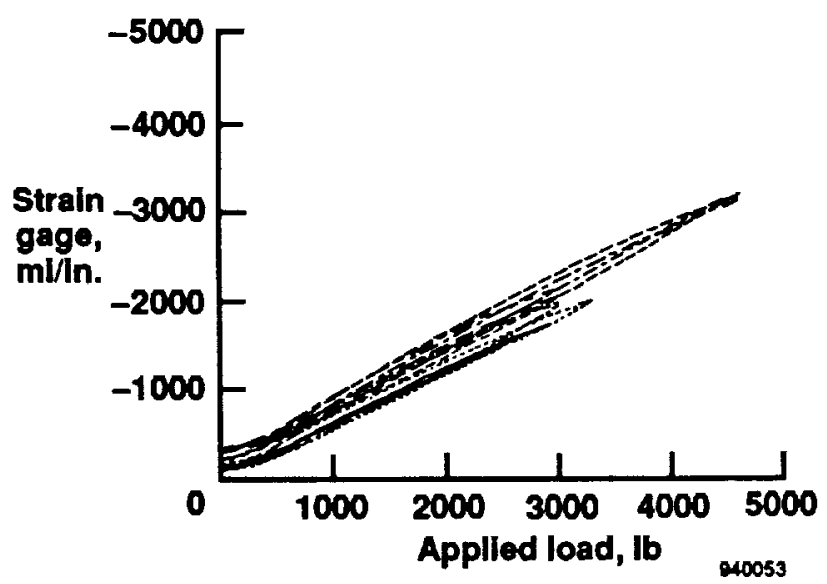

(a) Strain as a function of applied load.

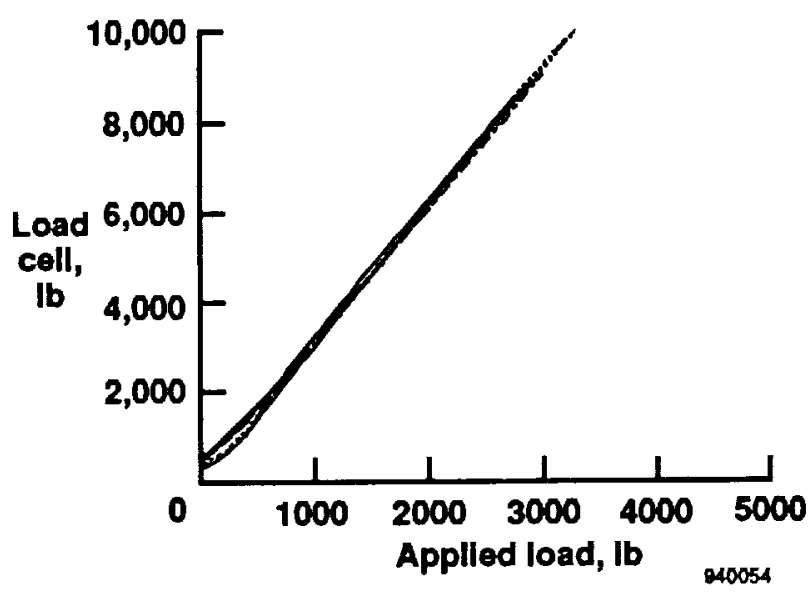

(b) Forward sway pad load as a function of applied load.

Figure 10. Test article load test data.

sway braces may be more dependent on sway brace stiffness that may change from pylon to pylon.

\section{Other Structural Considerations}

Other structural considerations such as structural dynamics, pylon design limits, composites inspection, and ground and flight durability were considered in the FTF-II structural design and attachment to the aircraft. Concems about structural dynamics were assessed, but were found to be minimal because of the stiff fixture structure and the attachment location of the fixture on the centerline of the aircraft. Accelerometers will be placed into the lower portion fixture to validate this assessment during envelope expansion flights.

The F-15 centerline pylon is ideal as an attachment point for the FTF-II because of its existing hardware with known structural and operational capabilities. The known capabilities of the pylon minimized efforts and concerns related to aircraft loads limits and aeroelasticity. The ultimate design loads of the F-15 pylon provided by McDonnell Douglas were found to be several times higher than worst-case fixture limit loads.

The overall durability and composite inspection techniques had a role in the structural design of fixture. These were addressed by high margins of safety and visual access to critical structural regions within the fixture. Special attention was given to flange thickness, fastener edge distances, and bond lines within the composite structure. Removable components and side panels allowed for easy visual inspection. Nondestructive visual and $x$-ray inspections of the FTF-II were made to verify the integrity of the structure and provide a baseline for future periodic inspections. 


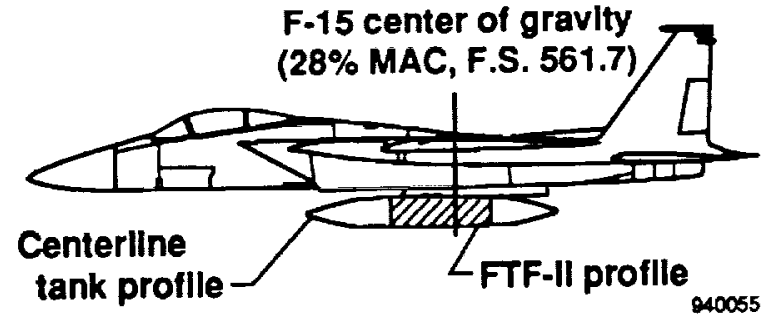

Figure 11. Side view of F-15.

\section{Aircraft Stability}

Since the FTF-II is mounted near the aircraft center of gravity (fig. 11) and has a smaller projected side area than the operational centerline tank, it was not expected that lateral-directional stability and control problems would limit the operational envelope. To verify this, directional stability for $1-g$, trim- $\alpha$ conditions was examined during the design process and addressed again during the flight envelope expansion, which will be discussed in a later section.

\section{Subsonic}

The data from the flight test report by the Air Force Flight Test Center on the operational envelope of the F-15B with and without the centerline fuel tank were obtained. ${ }^{10}$ Subsonic static directional stability flight data for the air-superiority configuration (no large stores or tanks), shown in figure 12, indicate that levels were above $0.002 \mathrm{deg}^{-1}$ with and without a centerline fuel tank. Computations using the asymmetric vortex lattice (AVL) aerodynamic analysis computer $\operatorname{code}^{17}$ were used to determine the approximate subsonic $C_{n_{\beta}}$ levels for the F-15B in the baseline, centerline fuel tank and fixture configurations. AVL results for the baseline F-15B show reasonable agreement with the Air Force data. In addition, AVL output for the centerline fuel tank and the fixture configurations showed slight increases in directional stability. Although such an increase was unexpected, these results continued to show agreement with Air Force data and provided sufficient confidence that the fixture would not significantly reduce aircraft stability margins at subsonic conditions.

\section{Supersonic}

Figure 12 also shows static directional stability fight data at supersonic speeds. As expected, static directional stability decreases with increasing supersonic Mach numbers while remaining positive out to the Mach number limit of the F-15. At $M=1.5$, the directional stability of the centerline fuel tank configuration is slightly higher than the stability of the air-superiority configuration. At $M>$ 1.5, the $C_{n_{\beta}}$ for the air-superiority configuration approaches levels as low as $C_{n_{\beta}} \approx 0.0005$. Although stability levels similar to those with the centerline fuel tank were expected with the fixture, estimates at supersonic speeds using the AVL code were not available because of

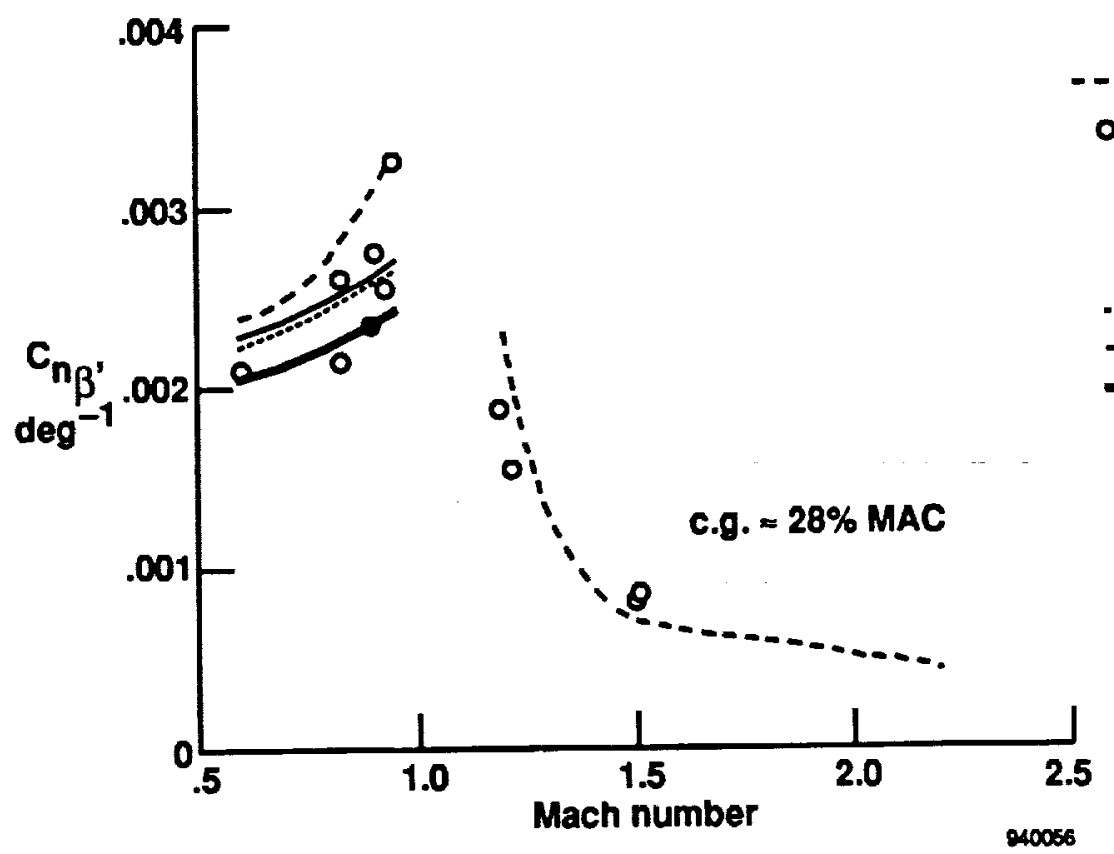

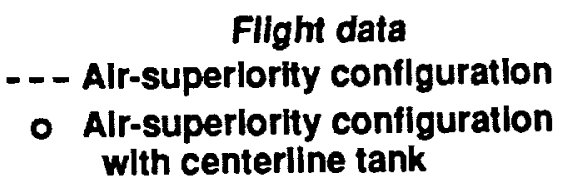

AVL predictions

...... F-15B with centerline tank F-15B with FTF-II Baseline F-15B alrcraft

Figure 12. F-15B static directional stability (modified from ref. 10). 
code limitations. Since predictions of supersonic static directional stability for the F-15B with the fixture were unavailable, a conservative envelope expansion was recommended at supersonic speeds.

\section{Operational Considerations}

Operational considerations can often include issues from maintenance to safety of flight, but these issues must be considered during the design phase of any effort. For example, mounting the FTF-II to the centerline pylon was very desirable for several reasons. The installation and removal times of the FTF-II were greatly reduced by using a proven aircraft attachment point with proven procedures that are familiar to an F-15 crew. In addition, operational emergency jettison capability of the centerline pylon with the fixture attached is retained. Jettison of the fixture would occur only under emergency conditions where a gear-up landing is necessary. Although no stores separation studies were conducted, the risks of an inadvertent jettison or an unexpected separation trajectory were assessed and found to be remote.

As discussed previously, the configuration flexibility and accessibility to experiments contained within the FTF-II were ongoing concerns during the design. Because of the modular composite construction, all of the fixture components can be replaced with smooth contoured surfaces that are ideal for aerodynamic studies. The vertical test article, nose section, splitter plate, noseboom, and side panels can be replaced with alternative configurations with no modifications to the primary structure and minimal additional analysis of the new configuration. All the fixture side panels are removable with quick internal access to experiments through the left side panels. Other considerations included easy access to avionics-instrumentation wiring within the fixture and to the pylon interface and provisions for mounting permanent avionicsinstrumentation and changing experimental hardware. A dolly was fabricated to perform both ground handling and aircraft loading to minimize the potential for damage to the composite structure.

\section{Flight Testing}

\section{Approach}

The envelope expansion of the F-15B/FTF-II configuration is planned in three phases. Phase 1 , which has been completed, consisted of flying the fixture uninstrumented on the F-15B to do envelope expansion and qualitative flow quality studies in $1-g$, trim- $\alpha$ flight up to $M=1.3$. As a precaution against unexpected loads or a reduction in stability, ${ }^{13}$ sideslip angle was restricted to $\pm 7.5^{\circ}$ and to those specified in the flight test requirements. In addition, sideslip maneuvers were limited to half-pedal inputs and were restricted in the transonic region.
Directional stability was evaluated by performing rudder doublets at two altitudes. The rudder doublets were performed with build-up points with respect to Mach number, rudder pedal position, and rate of rudder pedal input. These points were flown on the F-15B first with the centerline tank and then with the FTF-II.

Flow quality was documented using surface flow-visualization techniques to define surface flow streamlines. Tufts were attached on the left side of the fixture and pigmented oil or shear sensitive liquid crystals ${ }^{18}$ were applied on the right side of the fixture. Video and photo documentation of the results were obtained from another aircraft flying in close formation. Flight testing was accomplished at straight and level conditions, with and without the splitter plate installed onto the nose section.

Phase 2 will be performed with a fully instrumented FTF-II that will include an airdata probe. The airspeed envelope will be expanded out to the current F-15 empty centerline tank envelope of $M=1.8$ (fig. 6). Full expansion out to the fixture design limits of $800 \mathrm{KCAS}$ and $M=2.0$ will follow in phase 3. Envelope expansion will continue to include investigations related to directional stability, structures, and aerodynamics. Calibrated load cells will be located at the sway brace pads and surface pressures will be used to monitor in-flight side loads and the distribution of these loads. Combined boundary-layer and surfacepressure data and flow-visualization studies will be used to evaluate the flow quality and identify improvements to the fixture. The pressure data will be compared with recent benchmark F-104/FTF data. ${ }^{8}$

Standard techniques will be used to calibrate the F-15B and FTF-II airdata systems. Nose section surface temperature measurements will be monitored for possible expansion of the airspeed envelope beyond $M=2.0$. The levels of directional stability will also be monitored during the expansion process. The envelope expansion activities are expected to minimize most airspeed and operational limitations so that the FTF-II will be cleared for flight test within the full F-15B envelope.

\section{Phase-1 Results}

Six F-15B/FTF-II flights were accomplished with test points at altitudes of 20,000 and $30,000 \mathrm{ft}$ and airspeeds between $0.6 \leq M \leq 1.3$. One pilot was chosen to conduct the qualitative evaluations on lateral-directional stability. The pilot reported positive stability with a "deadbeat" (pilot's words) response to the rudder doublets, indicating a positively damped stable system up to $M=1.2$. At $M=$ 1.3 and $30,000 \mathrm{ft}$, the pilot reported the aircraft's response had become what he called "loose," but stability remained positive. These qualitative flight test results agree with the large decrease in directional stability flight data shown in 


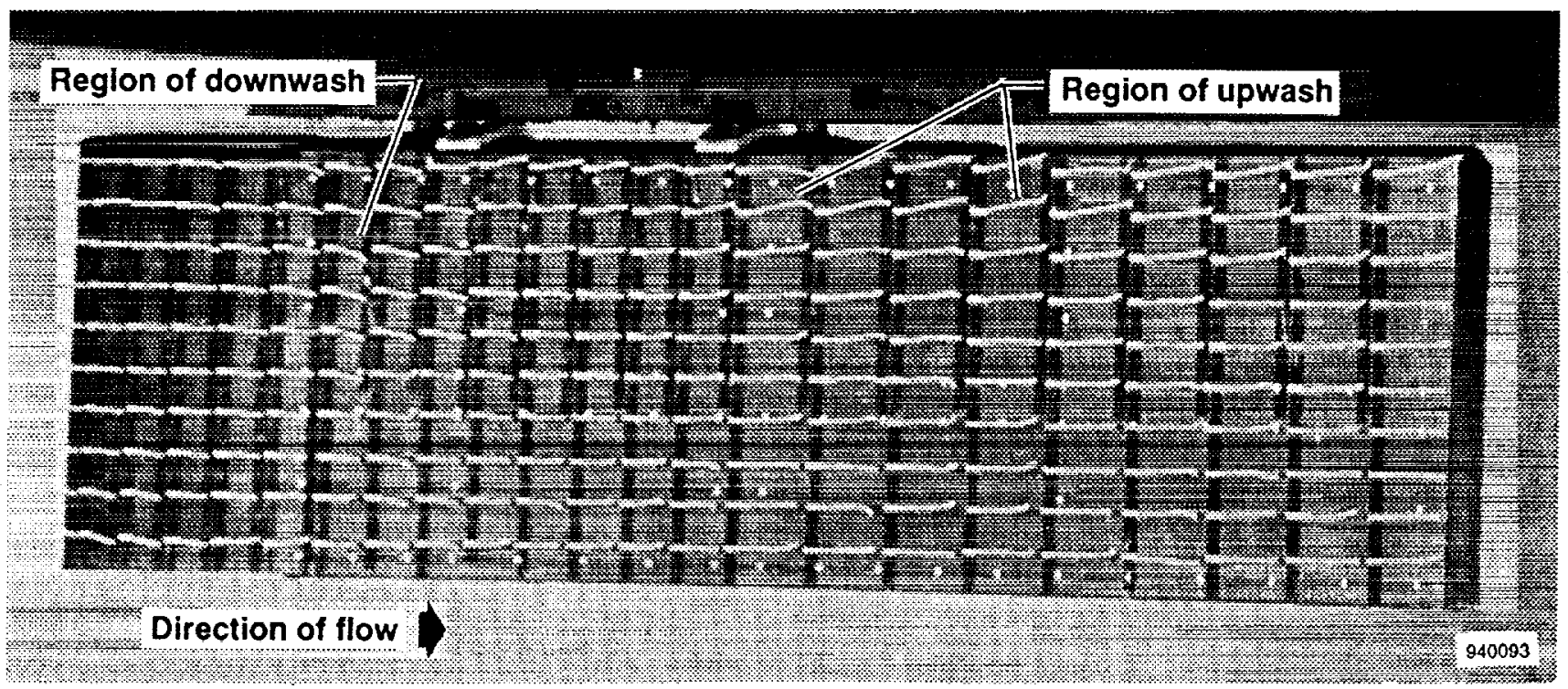

Figure 13. F-15/FTF-II flight test flow visualization results, left side view with tufts, $\alpha=2^{\circ}, \beta=0^{\circ}, M=0.80$.

figure 12 for the F-15B with and without the centerline fuel tank for $M>1.2$.

Video and still photographs of the tufts installed on the left side of the fixture, at $M=0.8$ and $30,000 \mathrm{ft}$ (fig. 13), showed smooth streamwise flow over most of the fixture with some minor downwash starting near the leading edge of the centerline pylon. The flow ncar the top of the fixture transitions to a slight upwash near midchord. Surface flow over the test article region with the splitter plate installed is predominantly streamwise and steady. The splitter plate provided a slight reduction in the downwash from the aircraft and centerline pylon as predicted from the water-tunnel results. In general, the subsonic flight results show good correlation with water-tunnel predictions with (fig. 6) and without the splitter plate installed on top of the nose section. At supersonic conditions, similar streamwise flow was observed with slightly more downwash and upwash over the upper regions of the fixture. Flow over the test article region remained predominantly streamwise during supersonic conditions.

Liquid crystals sensitive to shear forces ${ }^{18}$ were applied before several flights on a portion of the nose section to determine the regions of laminar and turbulent boundrylayer flow on the nose section. In-flight video and still photographs from another aircraft were used to document the flow conditions. Results from application of the liquid crystals are shown in figure 14 at $M=0.9$ and $30,000 \mathrm{ft}$. As shown, most of the turbulent flow present on the nose section resulted from forced transition using a grit strip and a piece of tape. Forced transition was used to verify that the liquid crystals properly identified regions of

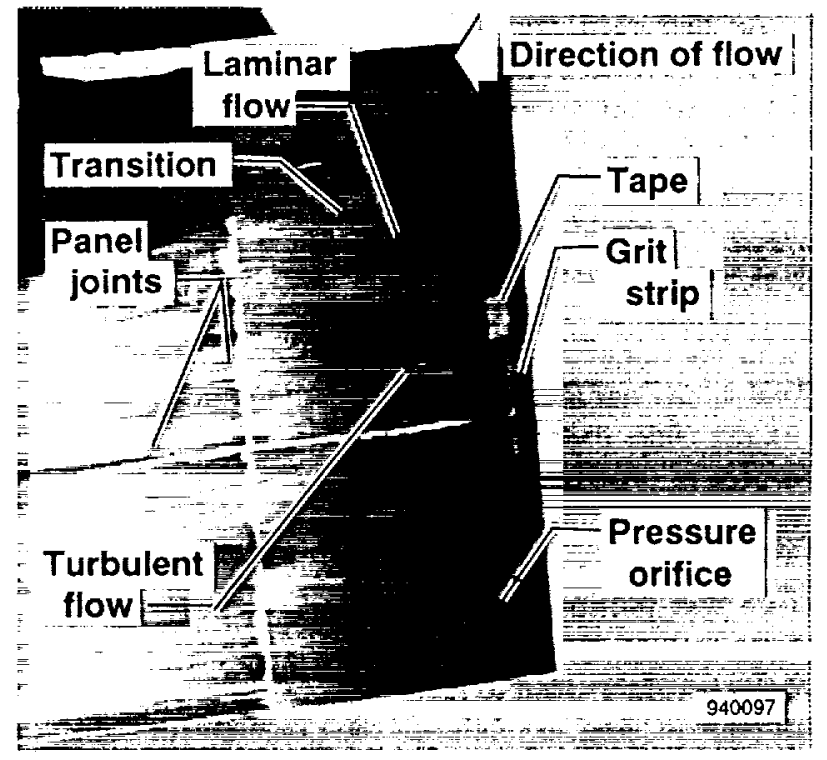

Figure 14. FTF-II nose section with liquid crystals, right side, $M=0.90$.

turbulent flow. A small turbulent wedge near the bottom of the nose section was the result of flow transition caused by a pressure orifice at this location. At subsonic flight conditions, the most aft location of transition ranged from $x / c=$ 0.10 to 0.12 . Transition as far aft as $x / c=0.16$ (nose section joint is at $x / c=0.175$ ) was observed at $M=1.1$.

\section{Concluding Remarks}

Flight testing of a second-generation flight test fixture (FTF-II) has successfully demonstrated stable flight to 
Mach 1.3 at $30,000 \mathrm{ft}$. Surface flow was documented as predominantly streamwise at subsonic speeds with downwash increasing in some areas at supersonic speeds. The presence of the splitter plate extending to $x / c=0.175$ slightly reduced some of the local downwash. Qualitatively, flow characteristics appear acceptable for a wide variety of aerodynamic and fluid mechanics research experiments, but more quantitative measurements will be required. Additional flight testing of the fixture with instrumentation is expected to expand the F-15B/FTF-II flight envelope to Mach 2.0.

The fixture development effort demonstrates that simple design and analysis techniques can be used to minimize the time and cost associated with the development of a flight test structure. Conservative design assumptions and analysis techniques, combined with ground simulation facilities, were used throughout. A prudent flight test approach was planned to complement these analyses by quickly validating ground predictions while safely expanding the flight envelope. This multidisciplinary approach was balanced so that all design goals were accomplished in a safe and timely manner.

\section{Acknowledgments}

The authors thank Edwin J. Saltzman (PRC Inc.) for his research and contributions toward determining aerodynamic loads and providing a historical perspective on past F-104/FTF reseanch. The authors also thank Glenn Maben (PRC Inc.) for his efforts on the design, analysis, and fabrication of the fixture.

\section{References}

${ }^{1}$ Meyer, Robert R., Jr., A Unique Flight Test Facility: Description and Results, NASA TM-84900, Nov. 1982.

${ }^{2}$ Montoya, Lawrence C., David A. Brauns, and Ralph E. Cissell, Flight Experience With a Pivoting Traversing Boundary-Layer Probe, NASA TM X-56022, Jan. 1974.

${ }^{3}$ Chiles, Harry R. and J. Blair Johnson, Development of a Temperature-Compensated Hot-Film Anemometer System for Boundary-Layer Transition Detection on HighPerformance Aircraft, NASA TM-86732, Aug. 1985.

${ }^{4}$ Moes, Timothy R. and Robert R. Meyer, Jr., In-Flight Investigation of Shuttle Tile Pressure Orifice Installations, NASA TM-4219, Sept. 1990.

${ }^{5}$ Saltzman, Edwin J. and John Hintz, Flight Evaluation of Splitter Plate Effectiveness in Reducing Base Drag at Mach Numbers From 0.65 to 0.90, NASA TM X-1376, May 1967.
'Trujillo, Bianca M. and Robert R. Meyer, Jr., In-Flight Load Testing of Advanced Shuttle Thermal Protection Systems, NASA TM-86024, Dec. 1983.

${ }^{7}$ Meyer, Robert R., Jr. and Jack Barneburg, In-Flight Rain Damage Tests of the Shuttle Thermal Protection System, NASA TM-100438, May 1988.

${ }^{8}$ Zuniga, Fanny A., Bianca T. Anderson, and Arild Bertelrud, Flight Test Results of Riblets at Supersonic Speeds, NASA TM-4387, June 1992.

'U.S. Air Force, "USAF Series F-15A/B/C/D Aircraft, Block 7 and Up, Flight Manual," TO 1F-15A-1, 1 July 1989.

${ }^{10}$ Hook, D. E., et al., "USAF Stability and Control DATCOM," U.S. Air Force Flight Dynamics Laboratory, Wright-Patterson AFB, OH 45433, Apr. 1978.

11Peterson, John B., Jr., A Comparison of Experimental and Theoretical Results for the Compressible TurbulentBoundary-Layer Skin Friction With Zero Pressure Gradient, NASA TN D-1795, Mar. 1963.

${ }^{12}$ Hoemer, Sighard F., Fluid-Dynamic Drag, Hoemer Fluid Dynamics, Albuquerque, NM 87120, 1965, pp. 17-19.

${ }^{13}$ Tanaka, Arthur Y. and Rodrigo J. Huete, "F/TF-15A Flying Qualities Air Force Development Test and Evaluation," AFFTC-TR-76-48, July 1977.

${ }^{14}$ Anon., "Fluid Forces and Moments on Flat Plates," Engineering Sciences Data Item No. 70015, Engineering Sciences Data Unit, London, Sept. 1970.

${ }^{15}$ Etkin, Bernard, Dynamics of Flight, John Wiley \& Sons, Inc., London, 1959, pp. 446-453 and 501-509.

${ }^{16}$ Meyer, Robert R., Jr. and V. Michael DeAngelis, "Flight-Measured Aerodynamic Loads on a 0.92 Aspect Ratio Lifting Surface," in YF-12 Experiments Symposium, Vol. 1, NASA CP-2054, Sept. 1978, pp. 73-94.

${ }^{17}$ Lamar, John E. and Blair B. Gloss, Subsonic Aerodynamic Characteristics of Interacting Lifting Surfaces With Separated Flow Around Sharp Edges Predicted by a Vortex-Lattice Method, NASA TN D-7921, Sept. 1975.

${ }^{18}$ Holmes, Bruce J., Peter D. Gall, Cynthia C. Croom, Gregory S. Manuel and Warren C. Kelliher, A New Method for Laminar Boundary Layer Transition Visualization in Fligh $\_$Color Changes in Liquid Crystal Coatings, NASA TM-87666, 1986. 
Public reporting burden for this collection of information is estimated to average 1 hour per response, Including the trine for reviewing instructions, searching existing data sources. gathering and malntaining the data needed, and completing and reviewing the collection of information. Send comments regarding this burden estimate or any other aspect of this collaction of Intormation. Including suggestions lot reducing this burden. to Whashington Headquarters Services, Directorate lor Information Operations and Reports, t215 Jeflerson Davis Higtwray, Sulte 1204, Arthgton, VA 22202-4302, and to the OHloe of Management and Budger. Papenwork Pleduction Project (0704-0188), Washington. DC 20503.

\begin{tabular}{|l|l|l|l}
\hline 1. AGENCY USE OWLY (Loove blank) & $\begin{array}{l}\text { 2. REPORT DATE } \\
\text { August } 1994\end{array}$ & $\begin{array}{l}\text { 3. AEPORT TYPE AND DATES COVERED } \\
\text { Technical Memorandum }\end{array}$ \\
\hline
\end{tabular}

4. TILLE AND SUBTTLE

August 1994

5. FUNDING NUMBERS

Development of a Low-Aspect Ratio Fin for Flight Research Experiments

6. AUTHOR(\$)

David M. Richwine (PRC Inc., Edwards, CA) and John H. Del Frate

(NASA Dryden Flight Research Center, Edwards, CA)

7. PERFORMING ORGANIZATION NAME(S) AND ADDRESS(ES)

8. PERFoAMING ORGANIZATION

REPORT NUMBER

NASA Dryden Flight Research Center

P.O. Box 273

H-1993

Edwards, California 93523-0273

9. SPONSORINGMONOTORING AGENCY NAME(S) AND ADDRESS(ES)

10. SPONSORINGMONTTORINC

AGENCY REPORT NUMBER

National Aeronautics and Space Administration

Washington, DC 20546-0001

NASA TM-4596

11. SUPPLEMENTARY NOTES

This was originally prepared as AIAA-94-2133 for the 6th Biennial Flight Test Conference, Colorado Springs, CO, June 20-23, 1994.

12.. DISTRIBUTION/AVAILABILTY STATENENT

12b. DISTRIBUTION CODE

Unclassified-Unlimited

Subject Category 02

13. ABSTRACT (Maximum 200 words)

A second-generation flight test fixture, developed at NASA Dryden Flight Research Center, offers a generic testbed for aerodynamic and fluid mechanics research. The new fixture, a low-aspect ratio vertical fin shape mounted on the centerline of an F-15B aircraft lower fuselage, is designed for flight research at Mach numbers up to 2.0 . The new fixture is a composite structure with a modular configuration and removable components for functional flexibility. This report describes the multidisciplinary design and analysis approach used to develop the fixture. The approach integrates conservative assumptions with simple analysis techniques to minimize the time and cost associated with its development. Presented are the principal disciplines required for this effort, which include aerodynamics, structures, stability, and operational considerations. In addition, preliminary results from the first phase of flight testing are presented. Acceptable directional stability and flow quality are documented and show agreement with predictions. Future envelope expansion activities will minimize current limitations so that the fixture can be used for a wide variety of high-speed aerodynamic and fluid mechanics research experiments.

14. SUBJECT TERMS Aerodynamic loads: F-15 directional stability; Flight test fixture; Flow visualization; Structural design; Structural ground testing; Water tunnel visualization studies

17. SECUATYY CLASSIFICATION OF AEPORT

Unclassified

NSN 7540-01-280-5500

18. SECUATY CLASSIFICATION
OF THIS PAGE
Unclassified

Unclassified

19. SECURTY CLASSIFICATION
OF ABSTRACT
Unclassified

Available from the NASA Center for AeroSpace Intomation, 800 Elkridge Landing Raad, Linthicum Heights, MD 21090; (301)621-0390
15. NUMBER OF PAGES 16

16. PAICE CODE

$\mathrm{AO} 3$

20. LIMTAATION OF ABSTRACT

Unlimited

Standard Form 298 (Rev. 2-89)

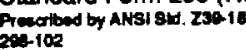

